\title{
Film Quantum Yields of Ultrahigh PAG EUV Photoresists
}

\author{
Robert Brainard, Craig Higgins, Elsayed Hassanein,* Richard Matyi and Andrea Wüest \\ College of Nanoscale Science and Engineering (CNSE), University at Albany, NY 12203 \\ ${ }^{*}$ Chemistry Department, Faculty of Science, Sohag University, Sohag, 82524 Egypt \\ $\ddagger$ \\ SEMATECH, Albany, NY 12203
}

\begin{abstract}
Base titration methods are used to determine C-parameters for twenty EUV photoresist platforms. X-ray reflectometry is used to measure the density of these resists, and leads to the determination of absorbance and film quantum yields (FQY). Ultrahigh levels of Photoacid Generator (PAG) show divergent mechanisms for production of photoacids beyond PAG concentrations of 0.35 moles/liter. The FQY of sulfonium PAGs level off, whereas resists prepared with iodonium PAG show FQYs that increase beyond PAG concentrations of 0.35 moles/liter, reaching record highs of 8-13 acids generated/EUV photons absorbed.
\end{abstract}

Keywords: EUV, Film Quantum Yield, Base Titration, Photoresists, Ultrahigh PAG Resists

\section{INTRODUCTION}

As the semiconductor industry continues to follow Moore's Law, the demand to print ever smaller features continues. Extreme ultraviolet (EUV) lithography is the leading candidate for $22 \mathrm{~nm}$ half pitch manufacturing. Despite recent advances in EUV resists, simultaneously achieving the required Resolution, Line-edge roughness (LER) and Sensitivity remains a significant issue for EUV (Fig. 1).[1] We refer to the competing nature of these three crucial elements as the RLS trade-off.[2] Gregg Gallatin and coworkers [2-4] have described the nature of the RLS trade-off using an analytical model. In Gallatin's work, as well as our own,[5] predictions have been made suggesting that the best way to get the required resolution, LER, and sensitivity all in the same resist is to create more acid/photon absorbed (increased film quantum yield).

We define the film quantum yield (FQY) as the number of acids generated in the film divided by the number of photons absorbed by the film (Figure 2). We assert that this quantity is more appropriate than the quantum yield as traditionally defined and that FQY is an important indicator of LER and RLS performance of EUV resists.[4]
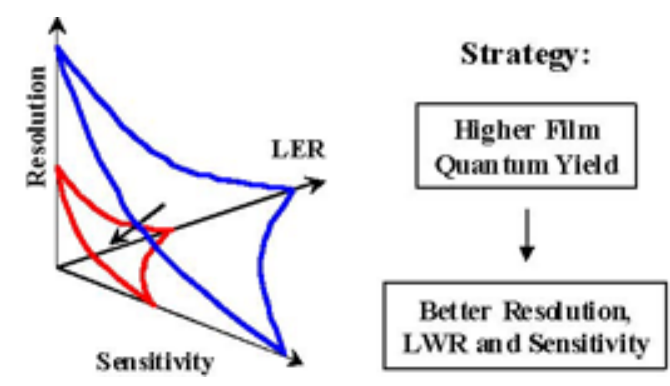

Fig. 1. Trade-off between three principal resist performance targets.

In traditional photochemical experiments, a compound is dissolved in a transparent solvent and irradiated. Photochemical reactions can, thus, be traced back to the absorption of a single photon by a single molecule. In EUV exposures, however, all components of the resist participate in the absorption of the light and interact with the photoelectrons.[6-13] Therefore, we study the absorption and acid generation in the whole film and call this ratio, the "film quantum yield" to distinguish it from the conventional photochemical definition. 
(A)

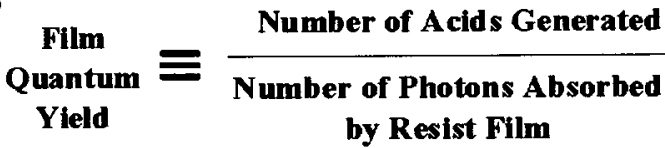

(B)

\begin{tabular}{l|c|c|c|} 
& \multicolumn{3}{c}{ Exposure Wavelength } \\
\cline { 2 - 4 } Resist & $248 \mathrm{~nm}$ & $193 \mathrm{~nm}$ & $13.5 \mathrm{~nm}$ \\
EUV-2D & 0.33 & 0.14 & 2.08 \\
\hline
\end{tabular}

Fig. 2. (A) Definition of film quantum yield. (B) Film quantum yield of EUV-2D at three wavelengths. [5]

Here, we describe our work in two parts. First, we evaluate the FQY of a resist system previously described by Intel, MIT-LL and NIST.[14-18] Secondly, we describe resists with ultrahigh levels of PAG and evaluate the C-parameter and FQY at these elevated PAG levels.

One of the simplest and most efficient ways to explore quantum yields is to prepare and evaluate a series of resists with different base levels.[19] In this work, we used a set of four resists with different base loadings so that we could use the Szmanda base-titration method to determine C-parameters.[19] The details of this approach are described in the experimental.

\section{RESULTS and DISCUSSION}

\subsection{ESCAP Photoresists}

Fig. 3 shows the chemical compounds described previously[14-18] and used in this work. We prepared resist formulations of two chemically amplified (CA) resist systems: ESCAP with either TBPI-PFBS or with TPS-PFBS as a PAG. We used an ESCAP terpolymer in combination with tetrabutyl ammonium hydroxide (TBAH) solution initially prepared as an ethyl lactate master batch. The solvent was a 50/50 blend of ethyl lactate and propylene glycol monomethylether acetate (PMA).

Twelve resists were prepared with $5,7.5$ and $10 \%$ iodonium PAG loading and four levels of base (Table 1). Resists were coated and imaged using the SEMATECH Albany Extreme Ultraviolet Micro-exposure Tool (AMET) to determine clearing doses (Eo), corrected C-parameters and film quantum yields as a function of PAG loading (Fig. 4). As expected, the resists get faster with increasing [PAG]. The C-parameter also appears to decrease with increasing [PAG] although the error bars in Fig. 4 show that the effect may be barely significant. We found that the film quantum yield increases linearly with PAG loading. This last result is not very surprising given the relationship between acid formation and [PAG] shown in eqn 1.[19]

Number of acids generated in film $=$

$\left[\right.$ PAG] $\left(1-\mathrm{e}^{(-\mathbf{C E})}\right)\left(6.02 \times 10^{23}\right)$

Where, $\mathrm{C}=\mathrm{C}$-parameter and $\mathrm{E}=$ dose.

Polymer

$65 / 20 / 15$

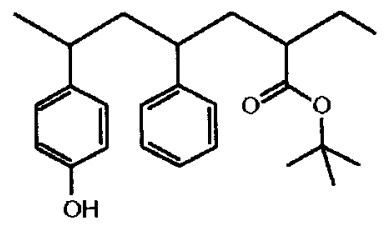

\section{Photoacid Generators (PAGs)}

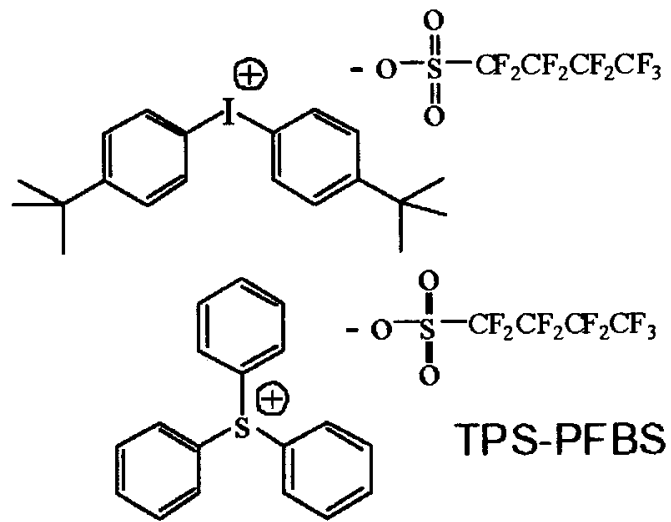

Base

TBAH

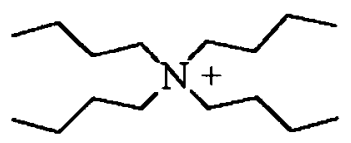

$\mathrm{OH}-$

Fig. 3. ESCAP resist components described previously as LUVR-99204 or LUVR-99258.[14-17]

\subsection{Ultrahigh PAG Resists}

2.2.1 Hypothesis: PAG Titration to determine number of photoelectrons.

One area of interest for our group is the determination of the number of photoelectrons generated during the exposure of chemically amplified resists to EUV radiation. Since the result shown in Fig. 4 shows that a doubling of [PAG] nearly doubles the FQY, we concluded that the PAG is the limiting reagent in the reaction between photoelectrons and PAGs (eqn 2). Therefore, we asked two hypothetical questions: (1) Would it be possible to increase the loading of PAG to the point where photoelectrons become the limiting reagent; and if so, (2) Could we then use the resulting film quantum yield $v$. [PAG] as a way to determine the number of photoelectrons generated (Fig. 5)? 


$$
\mathrm{PAG}+\mathrm{e}^{-} \rightarrow \mathrm{H}^{+}
$$

Table 1. Clearing doses of resists as a function of iodonium PAG and base loading.

\section{PAG \%}

\begin{tabular}{c|c|c|c|}
\multicolumn{1}{c}{ Base \% } & \multicolumn{1}{c}{5} & \multicolumn{1}{c}{7.5} & 10 \\
\cline { 2 - 4 } 0 & 0.5 & 0.4 & 0.35 \\
\cline { 2 - 4 } 0.17 & 1.4 & 1.2 & 0.95 \\
\cline { 2 - 4 } 0.34 & 3.4 & 2.4 & 1.9 \\
\cline { 2 - 4 } 0.5 & 4.6 & 3.7 & 2.9 \\
\cline { 2 - 4 } & &
\end{tabular}
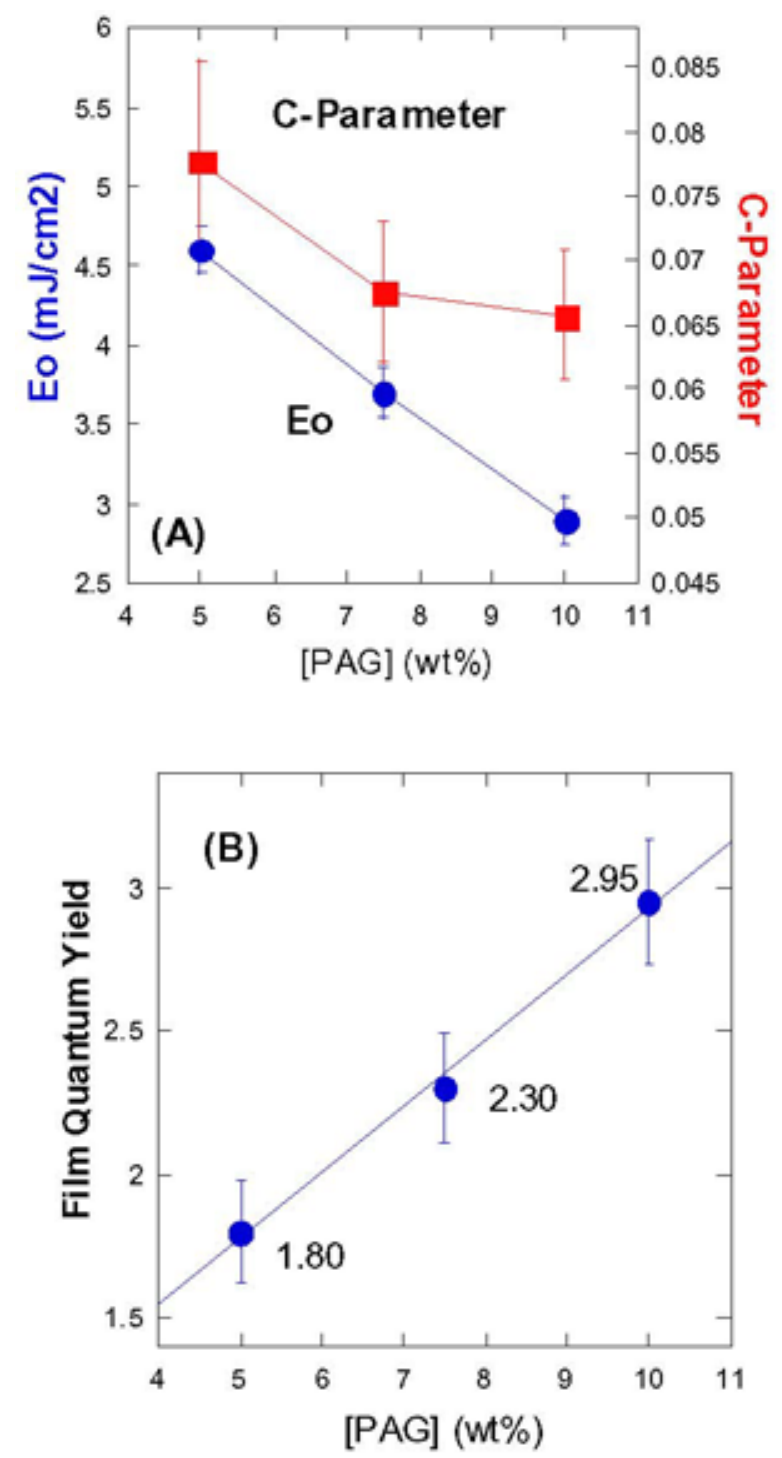

Fig. 4. Relationship between C-parameters, Eo's, film quantum yields $v s$. PAG concentration.

We prepared several resists using the iodonium and sulfonium PAGs (Figure 3) with loadings from 5 to 70 $\mathrm{wt} \%$, then tested their coating quality, outgassing, and unexposed film thickness loss (UFTL, Table 5). All ESCAP with TPS-PFBS exhibited good coatings, even with as much as $70 \mathrm{wt} \%$ PAG loading, while those with TBPI-PFBS exhibited good coatings up to $40 \mathrm{wt} \%$ PAG. Resists prepared with $50 \mathrm{wt} \%$ PAG gave poor coatings.

\subsubsection{Unexposed Film Thickness Loss (UFTL).}

Before performing imaging experiments, we evaluated the ultrahigh PAG formulations for UFTL or dark-loss performance. Resist films prepared with $15-50 \mathrm{wt} \%$ iodonium PAG (TBPI-PFBS) and 15-70 $w t \%$ sulfonium (TPS-PFBS) PAGs were coated and baked using Post-apply bake (PAB) and Post-exposure

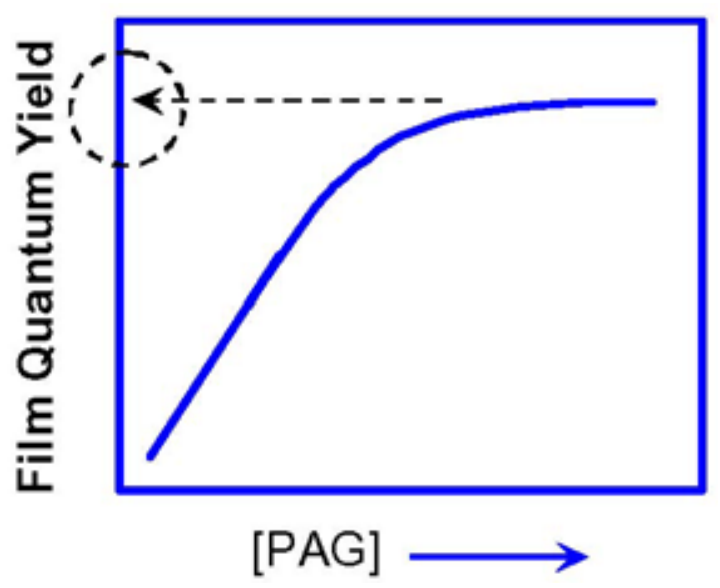

Fig. 5. Hypothesis prompting the investigation into the effect of ultrahigh levels of PAG on film quantum yield as a way to determine the number of photoelectrons generated during EUV exposure.

bake (PEB) conditions $\left(130^{\circ} \mathrm{C} / 60 \mathrm{~s}\right.$ followed by 130 ${ }^{\circ} \mathrm{C} / 90 \mathrm{~s}$ ) and film thickness was measured before and after $45 \mathrm{~s}$ development in either 0.26 or $0.13 \mathrm{~N}$ tetramethylammonium hydroxide (TMAH). UFTL results are shown in Table 2. All of the iodonium resists showed acceptable UFTLs of 6-17 $\AA$. The resist films prepared with the sulfonium PAG tend to have much greater UFTL values. Only the diluted $0.13 \mathrm{~N}$ developer gave acceptable UFTLs and only when the level of sulfonium PAG was less than 50 $\mathrm{wt} \%$. During imaging experiments, all resists prepared with sulfonium PAGs were developed using $0.13 \mathrm{~N}$ TMAH.

\subsubsection{Outgassing Tests.}

Outgassing measurements for ultrahigh iodonium and sulphonium PAG resists $(7.5,25$ and $40 \mathrm{wt} \%)$ were carried out using the EUV ROX tool at CNSE (Table 3).[20] The typical procedure is to expose resist films to $2.5 \mathrm{x}$ the clearing dose (Eo). Surprisingly, all resists passed the SEMATECH limit of $6.5 \times 10^{2}$ molecules $/ \mathrm{cm}^{2}$, even when the resists 
were dosed with $25 x$ Eo. Based on these results, we were able to perform exposure experiments on the SEMATECH EUV METs at Albany, NY (AMET) and at Lawrence Livermore National Laboratories, Berkeley, CA (BMET).

Table 2. Coating and Unexposed Film Thickness Loss (UFTL) observed for Ultrahigh PAG resists.

\begin{tabular}{|c|c|c|c|c|}
\hline & \multicolumn{4}{|c|}{ TBPI-PFBS (Iodonium, $\mathbf{I}+$ ) } \\
\hline $\begin{array}{c}\% \\
\text { PAG }\end{array}$ & Name & $\begin{array}{l}\text { Coat. } \\
\text { Qual. }\end{array}$ & $\begin{array}{c}\text { UFTL, A } \\
0.26 \mathrm{~N}\end{array}$ & $\begin{array}{c}\text { UFTL, A } \\
0.13 \mathrm{~N}\end{array}$ \\
\hline 5 & OS2 & Good & & \\
\hline 7.5 & OS1 & Good & & \\
\hline 10 & OS3 & Good & & \\
\hline 15 & OS4 & Good & 17 & 6 \\
\hline 20 & OS5 & Good & 14 & 6 \\
\hline 25 & OS6 & Good & 14 & 6 \\
\hline 30 & OS7 & Good & 12 & 7 \\
\hline 40 & OS8 & Good & & 9 \\
\hline 50 & OS9 & Poor & 11 & $\overline{8}$ \\
\hline 60 & OS10 & Poor & & \\
\hline 70 & OS11 & Poor & & \\
\hline & \multicolumn{4}{|c|}{ TPS-PFBS (Sulfon ium, $\mathbf{S}+$ ) } \\
\hline 5 & & Good & & \\
\hline 7.5 & OS-S1 & Good & & \\
\hline 10 & & Good & & \\
\hline 15 & OS-S2 & Good & 315 & 11 \\
\hline 20 & & Good & 318 & 13 \\
\hline 25 & OS-S3 & Good & 377 & 17 \\
\hline 30 & OS-S4 & Good & 501 & 21 \\
\hline 40 & OS-S5 & Good & 961 & 83 \\
\hline 50 & OS-S6 & Good & 1248 & 217 \\
\hline 60 & OS-S7 & Good & 1248 & 547 \\
\hline 70 & OS-S8 & Good & 1246 & 731 \\
\hline
\end{tabular}

Table 3. Outgassing Results from resists prepared with ESCAP Terpolymer (Figure 3) and either Iodonium TBPI-PFBS or Sulfonium TPS-PFBS PAGs. Outgassing values are reported as $10^{14}$ molecules $/ \mathrm{cm}^{2}$ for atomic mass units of 35-200, but without 44 AMU.

\begin{tabular}{|c|c|c|c|c|}
\hline PAG & $\begin{array}{c}\text { PAG } \\
(w t \%)\end{array}$ & $\begin{array}{c}2.5 x \\
\text { Eo }\end{array}$ & $\begin{array}{c}11 x \\
\text { Eo }\end{array}$ & $\begin{array}{c}\mathbf{2 5 x} \\
\text { Eo }\end{array}$ \\
\hline Iodonium & 25 & 2 & 2 & 4 \\
TBPI-PFBS & 40 & 3 & NA & NA \\
\hline Sulfonium & 25 & 2 & 3 & 5 \\
\hline TPS-PFBS & 40 & 4 & NA & NA \\
\hline
\end{tabular}

\subsubsection{Eos, C-Parameters and Film Quantum Yields.}

Based on coating quality, outgassing and UFTL performance, we selected seven resists using the iodonium PAG $(5,7.5,10,15,20,30$ and $40 \mathrm{wt} \%)$ and three resists using the sulfonium PAG (7.5, 15 and 30 $w t \%)$. We plotted the clearing doses for all resists prepared with a constant amount of base $(0.5 \%$ TBAH) in Fig. 6. Clearing doses determined on the Berkeley MET were reduced by a factor of 1.9 according to recent calibration results.[21] AMET clearing doses are reported as received. All clearing doses decrease with increasing [PAG], as expected. Exposures conducted with the iodonium PAGs were conducted using both the AMET and the BMET and are in good agreement. Resists prepared with sulfonium PAGs are slightly slower than those prepared with iodonium PAGs.

Fig. 7 shows the C-parameter for the resists prepared with iodonium and sulfonium PAGs as a function of PAG loading. The C-parameters for resists prepared with iodonium PAGs decrease with increasing PAG concentration up to about $0.35 \underline{M}$ PAG, thereafter, the C-parameters increase. The C-parameters for resists prepared with sulfonium PAGs show a significant decrease with increasing PAG concentration.

Fig. 8 shows the film quantum yield as a function of PAG concentration. The resists prepared with sulfonium PAGs reach a maximum FQY of 3-4.3 acids/photon absorbed, and exhibit the curvature predicted in our original hypothesis, shown in Fig. 5. Since there are only three points in this curve, however, we will hold off on drawing conclusions about the implications regarding the number of photoelectrons until more detailed experiments can be conducted.

Resists prepared with iodonium PAGs do not appear to reach a limiting value as predicted (Fig. 5) and as shown with sulfonium PAGs. Instead, the film quantum yields accelerate above concentrations of $0.35 \underline{M}$. The resists prepared with sulfonium PAGs and with relatively low levels of iodonium PAGs $(<0.35 \underline{M})$ appear to behave similarly-the $\mathrm{C}$-parameters decrease with increasing [PAG] and the film quantum yields increase monotonically up to PAG concentrations of $\sim 0.35 \underline{M}$. However, at concentrations above $0.35 \underline{M}$, the behaviors of the two types of PAG diverge. The FQY of the sulfonium PAGs level off, whereas the resists prepared from iodonium PAGs accelerate reaching the highest know film quantum yields of 8-13 acids/photos absorbed. The range in these values of FQY arises due to the differences between the AMET and BMET exposure tools. Despite the differences in results between the two microexposure tools, one conclusion is clear-the 
iodonium PAGs appear to generate acid by a mechanism that differs from that of the sulfonium PAG when the concentration of the PAG is very high $(>0.35 \underline{M})$.

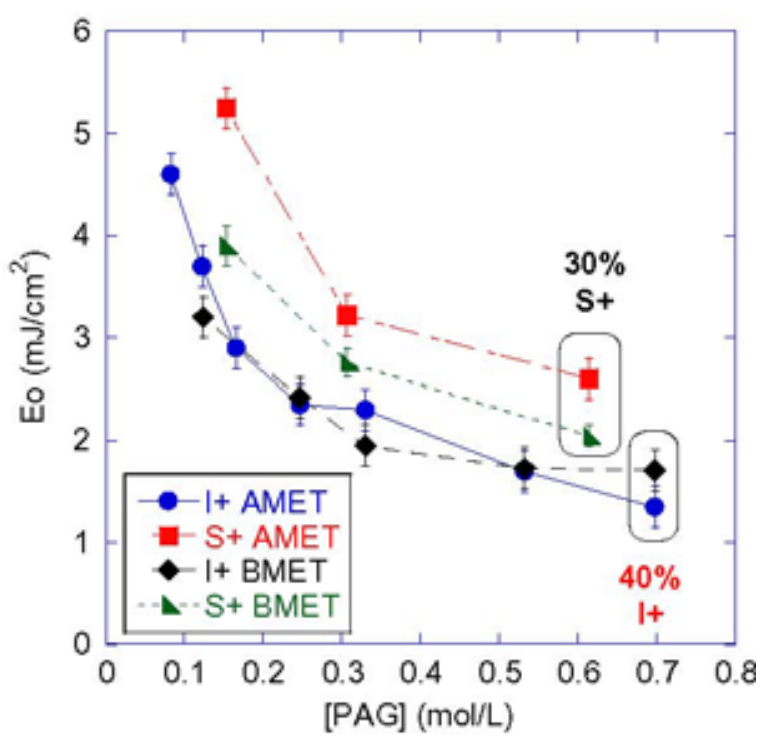

Fig. 6. Clearing doses vs. PAG concentration at constant base $(0.5 \%$ TBAH $)$.

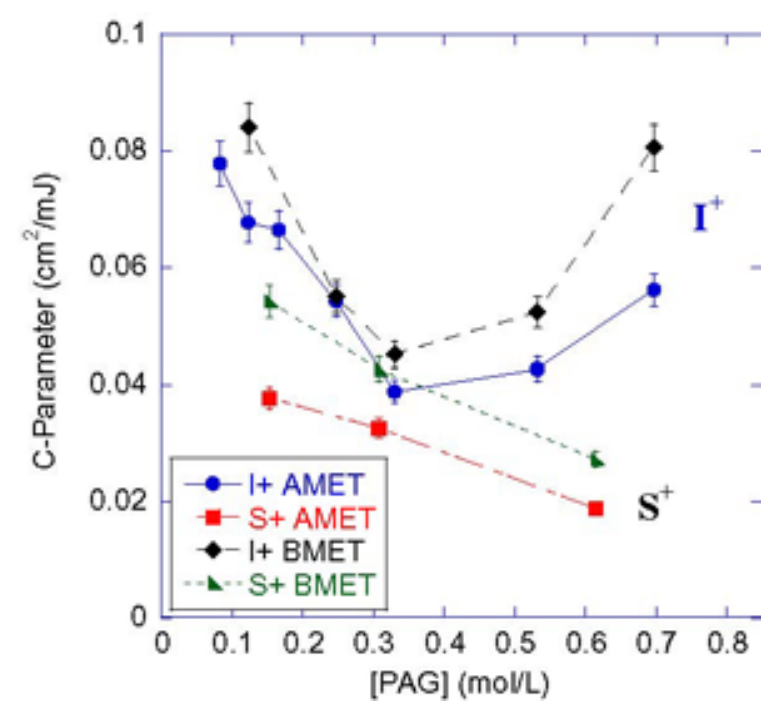

Fig. 7. C-Parameters vs. PAG concentration.

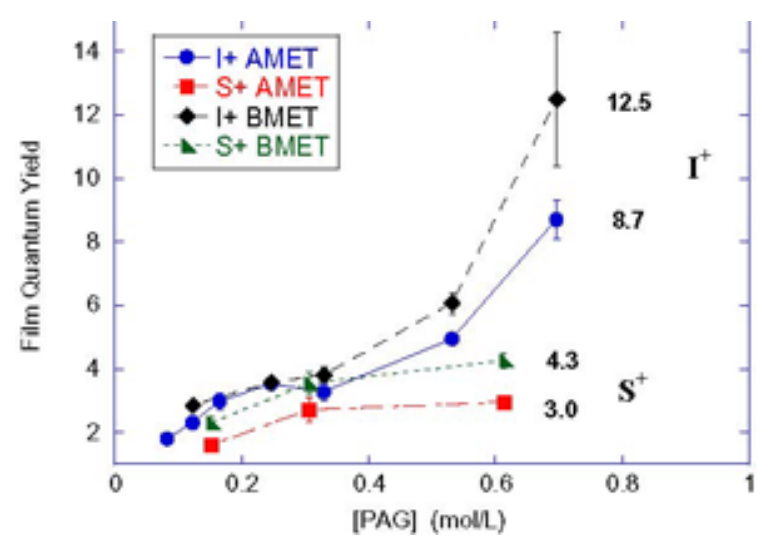

Fig. 8. Film Quantum Yield vs. PAG concentration.

\section{CONCLUSIONS}

We used base titration methods to determine C-parameters and film quantum yield for twenty EUV photoresist platforms. X-ray reflectometry was used to measure the film density leading to the determination of absorbance. EUV exposures at Albany and Berkeley were used to determine C-parameters leading to FQYs.

We found that it is possible to reach a film quantum yield as high as 3-4.3 acid/absorbed photon for resists prepared with $30 \%$ sulfonium PAG, but that the FQY appears to level off at concentrations of $\sim 0.35 \underline{M}$ sulfonium PAG. The C-parameter of resists prepared with ultrahigh concentrations of iodonium PAGs first decreases with [PAG], but then increases dramatically above $\sim 0.35 \underline{M}$ concentrations of PAG. The FQY reaches a maximum of 8-13 acids generated / photons absorbed when the concentration of PAG is $40 \mathrm{wt} \%$. This is the highest quantum yield yet described for an EUV photoresist. We think that EUV resists prepared with ultrahigh levels of PAG show great potential as a pathway to improve resolution, LER and sensitivity simultaneously, and we will continue our work with these interesting materials.

\section{EXPERIMENTAL}

\subsection{Materials.}

The published resists (OS resist), chemically amplified resist (CA), were composed of ESCAP terpolymers with either Di(4-tert-butylphenyl) iodonium perfluoro-1-butane- sulfonate (DTBI-PFBS) or Triphenylsulfonium perfluoro-1-butanesufonate (TPS-PFBS) as a PAG, tetrabutylammonium hydroxide base (TBAH), and 50/50 mixture solvent of ethyl lactate (EL) and propylene glycol methyl ether acetate (PGMEA). The ESCAP terpolymers were received from duPont Electronic Materials and were composed of 4-hydroxystyrene/styrene/t-butyl acrylate with 65/15/20 molar ratio, respectively. DTBI-PFBS and TPS-PFBS used in this study were purch ${ }^{n-\lambda}$ from Toyo Gosei. Initially, we formulated OS re 461 at different PAG levels based on solid from low $(5,7.5$ and $10 \mathrm{wt} \%)$ to high $(15,20,25,30,40,50,60$ and 70 wt $\%$ of resist solid), all at $0.5 \%$ TBAH loading. After we optimized the resist formulations based on the coating quality, outgassing testing, and dark film loss studies, we selected DTBI-PFBS loadings at 5, 7.5, 10, $15,20,30,40 \mathrm{wt} \%$ and TPS-PFBS at 7.5, 15 and 30 $w t \%$ for imaging experiments. For each of this PAG concentration we prepared a series of OS resists containing different base TBAH loadings. In all cases, 
the molar concentration of the base was kept to less than $15 \%$ of that of the PAG.

\subsection{Cleanroom Processing.}

Unless otherwise noted, photoresist samples were spin-coated on initially primed four- or eight-inch silicon wafers and subjected to post apply bake (PAB) to yield the film thickness of interest. The resist-coated wafer then exposed, subjected to a post-exposure bake (PEB) and finally developed utilizing single puddle of standard MF26A ${ }^{\mathrm{TM}}$ for 45 seconds. For TPS-PFBS OS-Type resists we used 50/50 diluted MF26A ${ }^{\text {TM }}$. Processing conditions for each platform are as follows: PAB: $130^{\circ} \mathrm{C} / 60 \mathrm{~s}$ FT: $125 \mathrm{~nm}$, PEB: 130 ${ }^{\circ} \mathrm{C} / 90 \mathrm{~s}$.

Exposures were performed at two different SEMATECH facilities: the EUV microexposure tool in Albany, NY (AMET) and the EUV microexposure tool in Berkeley, CA (BMET). The dose-to-clear for each resist and contrast curves (CCs) were evaluated initially at the AMET utilizing $10 \times 10$ experimentally array for this experiment. The AMET tool was operated at open field condition only (no mask). The later CCs for OS resists were determined at the BMET tool. OS resists at 5, 7.5 and $10 \mathrm{wt} \%$ DTBI-PFBS loadings were also imaged using dense line patterns at EUV BMET targeting possible process windows for both resolution and LER. BMET tool with numerical aperture (NA) of 0.25 was operated at annular conditions for these resists. Finally, we did outgassing testing for some OS resists having low and ultrahigh DTBI-PFBS or TPS-PFBS concentrations using the EUV ROX system at CNSE, Albany.[20]

\subsection{X-ray Reflectivity Film Density Measurements.}

Film densities were determined using specular $\mathrm{X}$-ray reflectometry analyses performed using a Bruker D8 Discover high resolution diffractometer operated in a $\theta-\theta$ geometry. X-rays from the line focus of a sealed copper tube were conditioned by a graded parabolic X-ray multilayer mirror before being diffracted by a two-reflection $\mathrm{V}$-groove beam compressor. The beam conditioner produced a monochromatic $\mathrm{Cu} \mathrm{K \alpha}{ }_{1}$ incident X-ray beam with approximate dimensions of $10 \mathrm{~mm}$ by $220 \mu \mathrm{m}$. The specularly-reflected incident beam was conditioned in angle by a $0.2 \mathrm{~mm}$ slit before being detected by a scintillation counter. Absorbers in the incident beam were used to automatically maintain the reflected intensity within the linear regime of the detector at all times. A knife-edge was positioned normal to the sample surface to intercept approximately $50 \%$ of the $\mathrm{X}$-ray beam propagating parallel to the surface at $2 \theta=$ 0 ; this permitted the reliable observation of the specular reflection profile below the critical angle for total external reflection from the photoresist layer. Specular XRR intensities were recorded using a step size of $0.005^{\circ}$ out to $8^{\circ} 2 \theta$, where all intensity oscillations arising from the photoresist film thickness were damped out by the effects of interfacial roughness. Following data collection, the specular XRR data were analyzed using the Bruker LEPTOS software package.

\subsection{C-Parameters and Film Quantum Yield.}

EUV film quantum yields were determined by systematic measurements for each resist platform. A series of 4-5 resist samples that were identical except for different base loadings were exposed to EUV radiation in order to establish the clearing doses, Eo's. The [base]/[PAG] ratio spanned over 0.0-0.25. The data was analyzed using the C-parameter (C) method developed by Szmanda et. al.[19] and the quantum yield method developed by us.[5] In this study, the C-parameter was determined by plotting the [base]/[PAG] ratio vs. EUV Eo resulting in a linear response. To determine $C$, initial slope of the obtained line from this plot was corrected for the EUV attenuation utilizing the film absorbance $(a)$ in base units:

$$
C=\text { slope } \cdot \frac{a}{\left(1-e^{-a}\right)}
$$

Using the measured $\mathrm{C}$, the amount of acid generated after EUV exposures was calculated from Equation 1. We computed resist absorbance at EUV by inputting the empirical formula and density $(\mathrm{g} / \mathrm{cm})$ into the CXRO Website.[22-23] The empirical formulas for each parent resist were used in combination with film density determined by small angle X-ray reflectometry. Combined with optical density information, we were able to calculate the number of Photons Absorbed and determine film quantum yield (Fig. 2).

\section{ACKNOWLEDGEMENTS}

We thank Patrick Naulleau, Matthew Malloy, Anwar Khurshid, Cecilia Montgomery, Andrew Rudack for performing lithograpic experiments. We thank Gregory Denbeaux and Alin Antohe for 
evaluating the outgassing performance of the high-PAG resists; and Andy Ma, Kim Dean and Charles Szmanda for helpful discussions. We thank duPont Electronic Materials for supplying the polymers.

We furthermore thank SEMATECH for partial financial support of this work.

\section{Disclaimer:}

Advanced Materials Research Center, AMRC, International SEMATECH Manufacturing Initiative, and ISMI are servicemarks of SEMATECH, Inc. SEMATECH, and SEMATECH logos are registered servicemarks of SEMATECH, Inc. All other servicemarks and trademarks are the property of their respective owners.

\section{NOTES and REFERENCES}

[1] Resist performance has been named one of the three most critical barriers to successful implementation of EUV lithography during the last four annual EUV Lithography Symposiums, 2004 2007.

[2] Gallatin, G. M., Proc. SPIE, 5753, 38-52 (2005).

[3] Gallatin, G. M., Naulleau, P., Brainard, R., "Fundamental limits to EUV photoresist," Proc. SPIE, 6519, 651911/1-651911/10. (2007).

[4] Gallatin, G. M., Naulleau, P., Brainard, R., Niakoula, D. and Dean, K., "Resolution, LER and Sensitivity Limitations of Photoresists," EUV Symposium, Sapporo, Jpn (2007).

[5] Brainard, R., Trefonas, P., Lammers, J., Cutler, C., Mackevich, J., Trefonas, A. and Robertson, S., Proc. SPIE, 5374, 74-85 (2004).

[6] Brainard, R. L., Henderson, C., Cobb, J., Rao, V., Mackevich, J. F., Okoroanyanwu, U., Gunn, S., Chambers, J. and Connolly, S., "Comparison of the lithographic properties of positive resists upon exposure to deep- and extreme-ultraviolet radiation," Journal of Vacuum Science \& Technology, B: Microelectronics and Nanometer Structures, 17(6), 3384-3389 (1999).

[7] Brainard, R. L., Barclay, G. G., Anderson, E. H., Ocola, L. E., "Resists for next generation lithography,". Microelectronic Engineering, 61-62, 707-715 (2002).

[8] Kozawa, T., Tagawa, S., "Basic aspects of acid generation processes in chemically amplified resists for electron beam lithography," Proc. SPIE 5753(Pt. 1, Advances in Resist Technology and Processing XXII),
361-367 (2005). Kozawa, T., Tagawa, S., "Basic aspects of acid generation processes in chemically amplified electron beam resist," Journal of Photopolymer Science and Technology, 18(4), 471-474 (2005).

[9] Tagawa, S., Nagahara, S., Iwamoto, T., Wakita, M., Kozawa, T., Yamamoto, Y., Werst, D. and Trifunac, A. D, "Radiation and photochemistry of onium salt acid generators in chemically amplified resists," Proc. of SPIE-The International Society for Optical Engineering, 3999(Pt. 1, Advances in Resist Technology and Processing XVII), 204-213 (2000). [10] Nakano, A., Okamoto, K., Yamamoto, Y., Kozawa, T., Tagawa, S., Kai, T., Nemoto, H., Shimokawa, T., "Deprotonation mechanism of poly(4-hydroxystyrene) and its derivative," Proc. of SPIE-The International Society for Optical Engineering, 5753(Pt. 2, Advances in Resist Technology and Processing XXII), 1034-1039 (2005).

[11] Kozawa, T., Saeki, A., Tagawa, S., "Modeling and simulation of chemically amplified electron beam, $\mathrm{x}$-ray, and EUV resist processes." Journal of Vacuum Science \& Technology, B: Microelectronics and Nanometer Structures--Processing, Measurement, and Phenomena, 22(6), 3489-3492 (2004).

[12] Yamamoto, H., Kozawa, T., Nakano, A., Okamoto, K., Tagawa, S., Ando, T., Sato, M., Komano, H., "Dependence of acid generation efficiency on the protection ratio of hydroxyl groups in chemically amplified electron beam, $x$-ray and EUV resists," Journal of Vacuum Science \& Technology, B: Microelectronics and Nanometer Structures--Processing, Measurement, and Phenomena, 22(6), 3522-3524 (2004).

[13] Kozawa, T., Saeki, A., Nakano, A., Yoshida, Y., Tagawa, S., "Relation between spatial resolution and reaction mechanism of chemically amplified resists for electron beam lithography," Journal of Vacuum Science \& Technology, B: Microelectronics and Nanometer Structures--Processing, Measurement, and Phenomena, 21(6), 3149-3152 (2003).

[14] Roberts, J. M., Meagley, R, Fedynyshyn, T. H., Sinta, R. F., Astolfi, D. K., Goodman, R. B., Cabral, A., "Contributions to innate material roughness in resist," Proc. of SPIE, 6153, 61533U/1-61533U/11 (2006).

[15] Fedynyshyn, T.H., Astolfi, D. K., Cabral, A. and Roberts, J., "PAG segregation during exposure affecting innate material roughness," Proc. SPIE, 6519, 65190X (2007). 
[16] Woodward, J. T., Fedynyshyn, T. H., Astolfi, D. K., Cann, S., Roberts, J. M., Leeson, M. J., "Component segregation in model chemically amplified resists,” Proc. of SPIE, 6519, 651915/1-651915/8 (2007).

[17] Fedynyshyn, T. H., Pottebaum, I., Cabral, A., Roberts, J., "Changes in resist glass transition temperatures due to exposure," Proc. of SPIE, 6519, 651917/1-651917/12 (2007).

[18] Hassanein, E.; Higgins, C.; Naulleau, P.; Matyi, R.; Gallatin, G.; Denbeaux, G.; Antohe, A.; Thackeray, J.; Spear, K.; Szmanda, C.; Anderson, C. N.; Niakoula, D.; Malloy, M.; Khurshid, A.; Montgomery, C.; Piscani, E. C.; Rudack, A.; Byers, J.; Ma, A.; Dean, K.; Brainard, R.; "Film Quantum Yields of EUV \& Ultra-High PAG Photoresists"; SPIE Proceedings, 6921 (2008).

[19] Szmanda, C. R, Brainard, R. L., Mackevich, J. F., Awaji, A., Tanaka, T., Yamada, Y., Bohland, J., Tedesco, S., Dal'Zotto, B., Bruenger, W., Torkler, M., Fallmann, W., Loeschner, H., Kaesmaier, R., Nealey, P. M., Pawloski, A. R., "Measuring acid generation efficiency in chemically amplified resists with all three beams,” Journal of Vacuum Science \& Technology, B: Microelectronics and Nanometer Structures, 17(6), 3356-3361 (1999).

[20] Denbeaux, G.; Garg, R.; Waterman, J.; Mbanaso, C.; Netten, J.; Brainard, R.; Fan, Y.-J.;
Yankulin, L.; Antohe, A.; DeMarco, K.; Jaffe, M.; Waldron, M.; Dean, K.; "Quantitative measurement of EUV resist outgassing”; SPIE Proceedings (2007), 6533, 653318/1-653318/5; Dean, Kim R.; Denbeaux, Gregory; Wuest, Andrea; Garg, Rashi; "EUV resist outgassing : how much is too much?”; J. Photopoly. Sci. Tech. (2007), 20(3), 393-402.

[21] Contrast curve experiments were conducted during January 2008. Patrick Naulleau announced during the EUVI Resist workshop, SPIE 2/28, to bring exposures in line with recent calibration experiments, doses determined prior to $2 / 28$ should be divided by 1.9 .

[22] CXRO website: http://henke.lbl. gov/optical_constantsT. Also see: Henke, B. L., Gullikson, E. M. and Davis, J. C., " $X$-ray interactions: photoabsorption, scattering, transmission, and reflection at $E=50-30000 \mathrm{eV}, \mathrm{Z}=1-92$," Atomic Data and Nuclear Data Tables Vol. 54 (no.2), 181-342 (July 1993).

[23] Chandhok, M., Cao, H., Wang, Y., Gullikson, E. M., Brainard, R. L., Robertson, S. A., "Techniques for directly measuring the absorbance of photoresists at EUV wavelengths," Proc. of SPIE, 5374, 861-868 (2004). 